\title{
Escherichia coli infection activates the production of IFN- $\alpha$ and IFN- $\beta$ via the JAK1/STAT1/2 signaling pathway in lung cells
}

\author{
Yan Jin ${ }^{1} \cdot$ Ziyi Jia $^{1} \cdot$ Quan Cai ${ }^{1} \cdot$ Yanfei Sun ${ }^{1} \cdot$ Zhi Liu $^{1}{ }^{\mathbb{C}}$ \\ Received: 10 April 2021 / Accepted: 2 September 2021 / Published online: 15 September 2021 \\ (c) The Author(s), under exclusive licence to Springer-Verlag GmbH Austria, part of Springer Nature 2021
}

\begin{abstract}
Escherichia coli infections can result in lung injury, which may be closely linked to the induction of interferon secretion. The Janus kinase (JAK)/signal transducer and activator of transcription (STAT) pathway is one of most important pathways that regulate interferon production. Thus, the present study aimed to dissect whether $E$. coli infections can regulate interferon production and the underlying mechanisms. For this aim, two lung cell lines, a human bronchial epithelial cell line transformed with Ad12-SV40 2B (BEAS-2b) and a human fetal lung fibroblast (HFL1) cell line, were used. The effects of $E$. coli infections on interferon production were studied using qRT-PCR, Western blot, and siRNA knockdown assays. $E$. coli infections remarkably promoted the expression levels of IFN- $\alpha$, IFN- $\beta$, and ISGs. Major components of the JAK/STAT pathway, including JAK1, STAT1, and STAT2, were demonstrated to be regulated by $E$. coli infections. Importantly, knockdown of JAK1, STAT1, and STAT2 abolished the induction of IFN- $\alpha$, IFN- $\beta$, and ISGs by $E$. coli. Therefore, experiments in the present study demonstrated that $E$. coli infections remarkably promoted interferon production in lung cells, which was closely regulated by the JAK/STAT signaling pathway. The findings in the present study are useful for further understanding the pathogenesis of $E$. coli infections in the lung and finding novel therapies to treat $E$. coli-induced lung injury.
\end{abstract}

Keywords Escherichia coli $\cdot$ IFN- $\alpha$ and IFN- $\beta \cdot$ JAK1/STAT1/2 signaling $\cdot$ Lung cell line $\cdot$ Protection

\section{Introduction}

The lung is one of the major organs in the body and is responsible for transferring oxygen from the atmosphere into the bloodstream (Mullassery and Smith 2015). Acute lung injury (ALI) is a common disease and a major cause of morbidity and mortality and is characterized by pulmonary inflammation and oxidative stress (Liu et al. 2018a). The incidence of ALI and its mortality are increasing (Rubenfeld et al. 2005). It was reported that mortality caused by ALI could be $\sim 40 \%$, with a more than $50 \%$ in-hospital mortality rate, although supportive care has been largely improved (Zhu et al. 2014). In the United States, it was reported that

Handling editor: S. Su.

\section{Zhi Liu}

liuzhuforw2@163.com

1 Department of Emergency, The First Affiliated Hospital of China Medical University, No. 155 Nanjing North Street, Heping District, Shenyang 110001, People's Republic of China the incidence of ALI and acute respiratory distress syndrome (ARDS) was 78.9 and 58.7 cases per 100,000 individuals yearly in patients older than 15 years (Suresh et al. 2000). Thus, a greater understanding of ALI is beneficial for developing novel medicines to treat severe diseases.

The agents causing ALI are multitudinous and include smoking (Gotts et al. 2018), inflammation (Hamacher et al. 2017), immunity disruption (Grommes and Soehnlein 2011), viral infections (Gregory and Kobzik 2015), and bacterial infections (Wan et al. 2016). Escherichia coli is one of the most common pathogens causing intestinal diseases (Liu et al. 2018b). Recently, accumulating evidence has indicated that $E$. coli can cause acute lung injury (Liu et al. 2018b). E. coli infects the lung, which results in pulmonary capillary endothelial damage, thus leading to permeability edema (Ye and Liu 2020). The tissue damage caused by E. coli in the lung is mainly due to the induction of interferon production, especially inflammation (Aulakh et al. 2014). However, how E. coli regulates interferon production in the lung remains unclear.

The JAK/STAT pathway is one of most important innate immune signaling pathways and was discovered through 
a study that linked interferon-responsive genes to signal transduction (Coskun et al. 2013). Among them, IFN- $\alpha$ and IFN- $\beta$ are the main components in innate immunity signaling. This pathway plays an important role in multiple physiological activities, including obesity and diabetes (Gurzov et al. 2016), rheumatoid arthritis (Malemud 2018), skeletal muscle pathophysiology (Moresi et al. 2019), and neuroinflammatory diseases (Yan et al. 2018). It was found that the regulation of innate immunity by $E$. coli is related to the JAK/STAT pathway (Ho 2017). Therefore, in the present study, we aimed to investigate the effects of $E$. coli infection on the production of IFN- $\alpha$ and IFN- $\beta$ in lung cell lines. $E$. coli infection remarkably induced IFN- $\alpha$ and IFN- $\beta$ production in lung cell lines via the JAK1/STAT1/2 signaling pathway. The findings in this study will provide useful information for studying the pathogenesis of E. coli-induced ALI and developing novel medicines to treat this difficult disease.

\section{Materials and methods}

\section{Reagents}

LB broth (catalog\# ST156, Shanghai, China), BeyoECL Plus (catalog\# P0018S), Bradford protein assay kit (catalog\# P0006), BeyoFast ${ }^{\mathrm{TM}}$ SYBR Green qPCR Mix (2X, catalog\# D7260), penicillin-streptomycin (catalog\# C0222), fetal bovine serum (FBS, catalog\# C0225), Beyozol (cata$\log \#$ R0011), BeyoRT TM II cDNA synthesis reagent (cata$\log$ \# D7168M), RIPA lysis buffer (catalog\# P0013C), and bovine serum albumin (BSA, catalog\# ST025-5 g) were purchased from Beyotime Biotechnology. Phosphate-buffered saline (PBS) was purchased from Thermo Fisher Scientific (pH 7.4, catalog\# 10010072). Dulbecco's modified Eagle's medium (DMEM) was purchased from Thermo Fisher Scientific (catalog\# 11995073). BEGM media with SingleQuot kit additives were purchased from Lonza (catalog\# CC-3170, Walkersville, MD). Human fibronectin (catalog\# PHE0023) was purchased from Thermo Fisher Scientific (catalog\# PHE0023, Waltham, MA). Bovine collagen type I was purchased from STEMCELL (catalog\# 07001, STEMCELL). Anti-IFN- $\alpha$ polyclonal antibody (catalog\# 66162-1Ig, Proteintech), Anti-IFN- $\beta$ polyclonal antibody (catalog\# 27506-1-AP, Proteintech), Anti-JAK1 (rabbit monoclonal, catalog\# ab133666), anti-STAT1 (rabbit monoclonal, catalog\# ab234400), anti-GAPDH (rabbit monoclonal, catalog\# ab8245), and anti-STAT2 (rabbit monoclonal, catalog\# ab32367) were purchased from Abcam.

\section{Cell culture}

The BEAS- $2 b$ cell line (a human nontumorigenic lung cell line) and human fetal lung fibroblast 1 (HFL1) cell line have been used in lung inflammation studies for a long time (Feng et al. 2012; Kikuchi et al. 2009). The two cell lines were obtained from the bioresource bank of the First Affiliated Hospital of China Medical University. The BEAS-2b cell line was maintained in BEGM media with SingleQuot kit additives in $75 \mathrm{~cm}^{2}$ Falcon tissue culture-treated flasks (Thermo Fisher Scientific, Waltham, MA) at $37{ }^{\circ} \mathrm{C}$ and 5\% $\mathrm{CO}_{2}$. BEGM containing human fibronectin $(0.01 \mathrm{mg} / \mathrm{mL})$, bovine collagen type I $(0.03 \mathrm{mg} / \mathrm{mL})$, and BSA $(0.01 \mathrm{mg} /$ $\mathrm{mL}$ ) was used to coat culture vessels for at least $2 \mathrm{~h}$ at $37^{\circ} \mathrm{C}$ prior to seeding cells. The HFL1 cell line was cultured in DMEM supplemented with $1 \%$ penicillin-streptomycin $(\mathrm{P} / \mathrm{S})$ and $10 \% \mathrm{FBS}$ at $37^{\circ} \mathrm{C}$ and $5 \% \mathrm{CO}_{2}$. The medium was replaced every 2 or 3 days. Both cell lines were subcultured when the confluence reached more than $90 \%$.

\section{Bacteria culture and cell infection}

Escherichia coli (strain O55:B5) was obtained from the Bioresource Center of the First Affiliated Hospital of China Medical University. E. coli was cultured in LB broth media at $37{ }^{\circ} \mathrm{C}$ overnight. The number of bacteria was counted spectrophotometrically at an optical density of $600 \mathrm{~nm}$ (OD600). For in vitro infections, bacteria were suspended in culture medium at a multiplicity of infection (MOI) of 100. After $3 \mathrm{~h}$ of infection, infected monolayers were washed 4 times with phosphate-buffered saline (PBS) and incubated in cell culture medium. $E$. coli-infected cells were incubated $24 \mathrm{~h}$ after invasion, followed by washing and lysis for subsequent assays.

\section{Knockdown via siRNA}

Small interfering RNAs (siRNAs) targeting JAK1, STAT1, and STAT2 were designed using the siDESIGN Center of Dharmacon, and they were synthesized by Biosyntech (Suzhou, China). BEAS-2b or HFL1 cells $\left(2 \times 10^{5}, 60-80 \%\right.$ confluence) were added to a 12 -well plate (Corning) in $1 \mathrm{~mL}$ of the corresponding media. After $24 \mathrm{~h}$, when confluence reached $60-80 \%$, control, JAK1, STAT1, and STAT2 siRNA knockdown assays (defined as si-scramble, siJAK1, siSTAT1, and STAT2, respectively) were carried out according to the manufacturer's protocol. The cells were harvested after $24 \mathrm{~h}$ of incubation for subsequent experiments. The sequences of siRNAs are listed in Table 1.

\section{RNA isolation and RT-PCR}

Total RNA was isolated from BEAS-2b and HFL1 cell lines using Beyozol reagent (Beyotime Biotechnology). The quantification of total RNA was performed using NanoDrop $^{\text {TM }}$ 2000/2000c spectrophotometers (Thermo Fisher Scientific). Subsequently, total RNA was converted to cDNA 
Table 1 The sequences of siRNAs used in the present study

\begin{tabular}{lll}
\hline Gene name & & Sequence $\left(5^{\prime} \rightarrow 3^{\prime}\right)$ \\
\hline Jak1 & Sense & CCACAUAGCUGAUCUGAAAUU \\
& Anti-sense & UUUCAGAUCAGCUAUGUGGUU \\
STAT1 & Sense & CCACAUAGCUGAUCUGAAAUU \\
& Anti-sense & UUUCAGAUCAGCUAUGUGGUU \\
STAT2 & Sense & CCACAUAGCUGAUCUGAAAUU \\
& Anti-sense & UUUCAGAUCAGCUAUGUGGUU \\
\hline
\end{tabular}

using BeyoRT ${ }^{\mathrm{TM}}$ II cDNA synthesis reagent according to the manufacturer's protocol. qRT-PCRs were carried out in a total reaction volume of $10 \mu \mathrm{L}$ containing $2 \times$ BeyoFast $^{\mathrm{TM}}$ SYBR Green qPCR Mix (2X), $8 \mu \mathrm{M}$ each of sense and antisense primers and $1 \mu \mathrm{L}$ of cDNA using the Roche LightCycler ${ }^{\circledR} 480$ instrument (Roche Applied Science, Indianapolis, Ind.). Primers used for qRT-PCR are listed in Table 2. The relative expression of mRNA was calculated using the $2^{-\Delta \Delta}$ threshold cycle $(\mathrm{Ct})$ (Livak) method. The RT-PCRs were performed in triplicate for each of the three independent samples.

\section{Western blotting (WB) analysis}

After treatment, the cells were washed and rinsed with cold PBS, followed by the addition of RIPA lysis buffer. Proteins were harvested in RIPA lysis buffer. Cell suspensions were centrifuged at $10,000 \times g$ for $20 \mathrm{~min}$ at $4{ }^{\circ} \mathrm{C}$. Protein was quantified using a Bradford protein assay kit. Subsequently, $30 \mu \mathrm{g}$ protein samples were electrophoresed in $12 \%$ sodium dodecyl sulfate-polyacrylamide gels and transferred to polyvinylidene difluoride membranes (Millipore, Billerica, MA, USA). Then, membranes were blocked using PBS containing $0.05 \%$ Tween-20 (Sigma, PBST) and 5\% skim milk for $1 \mathrm{~h}$ at room temperature, followed by incubation with 1:1000 dilutions each of anti-IFN- $\alpha$, anti-IFN- $\beta$, anti-JAK1, anti-STAT1, anti-STAT2, and anti-GAPDH at $4{ }^{\circ} \mathrm{C}$ overnight. Then, the membranes were washed with PBST three times and incubated with the appropriate secondary horseradish peroxidase-conjugated IgG antibody (R\&D Systems) for $1 \mathrm{~h}$ at room temperature. The protein bands on the membrane were detected using an ECL-Plus Western blot detection system according to the manufacturer's instructions.

\section{Statistical analysis}

Data are expressed as the mean \pm standard deviation (SD). Differences between 2 groups were assessed by a two-tailed unpaired Student's $t$ test when data were distributed normally. Analysis of variance with Tukey's multiple-comparisons test was used to evaluate experiments involving multiple groups. $P$ value $<0.05$ was considered significant.

\section{Results}

\section{E. coli infections increased the expression levels of IFN- $\alpha$ and IFN- $\beta$ in lung cell lines}

To investigate the effects of E. coli infections on interferon production in lung cells, we tested the mRNA levels of IFN- $\alpha$ and IFN- $\beta$ using qRT-PCR. E. coli infections $\left(5 \times 10^{4}\right.$ and $\left.1 \times 10^{5} \mathrm{CFU}\right)$ significantly increased
Table 2 The sequences of primers used in the present study

\begin{tabular}{lllll}
\hline Gene name & & Sequence $\left(5^{\prime} \rightarrow 3^{\prime}\right)$ & $\begin{array}{l}\text { PCR product } \\
\text { size }(\mathrm{bp})\end{array}$ & Tm \\
\hline Jak1 & Sense & GGAGGCGGGATGCATTTCTG & 126 & 61.45 \\
\multirow{2}{*}{ STAT1 } & Anti-sense & GAAGCGTGTGTCTCAGAAGC & & 59.21 \\
& Sense & GCATCGAGCGCACAAAGTTA & 82 & 59.56 \\
STAT2 & Anti-sense & ACCAGTAGGGTTGAGGGACA & & 59.81 \\
& Sense & TTTACTCGCACAGCCTCCTG & 128 & 60.04 \\
IFN- $\beta$ & Anti-sense & GATCCTGAATGTCCCGGCAG & & 60.53 \\
& Sense & AGTAGGCGACACTGTTCGTG & 173 & 55 \\
IFN- $\alpha$ & Anti-sense & GCCTCCCATTCAATTGCCAC & & 55 \\
& Sense & TTCGTATGCCAGCTCACCTT & 167 & 50 \\
MX1 & Anti-sense & GGATCAGTCAGCATGGTCCT & & 55 \\
& Sense & CCGAAACTGAATTGTCCGGG & 123 & 55 \\
ISG20 & Anti-sense & TGAATGGGGAATCGGAAGGC & & 55 \\
& Sense & ATCCCAGCCCTATTCCTGGT & 517 & 55 \\
IFIT1 & Anti-sense & CAGACCCTCCTCCCCATACA & & 60 \\
& Sense & AGTGGAGATGTGTACAAATGGTG & 229 & 43 \\
& Anti-sense & GCTCTTCAGGGCTTCCTCATT & & 52 \\
\hline
\end{tabular}




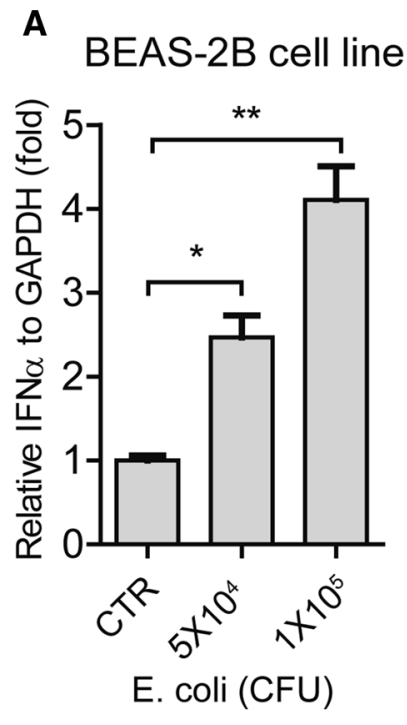

E

BEAS-2B cell line

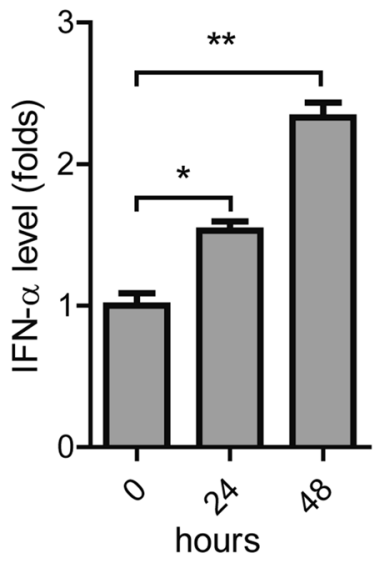

\begin{tabular}{cccc} 
I & \multicolumn{3}{c}{ BEAS-2B cell line } \\
& 0 & 24 & 48
\end{tabular}

IFN- $\alpha$

IFN- $\beta$

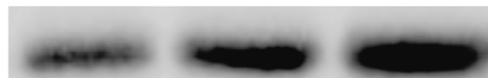

GAPDH

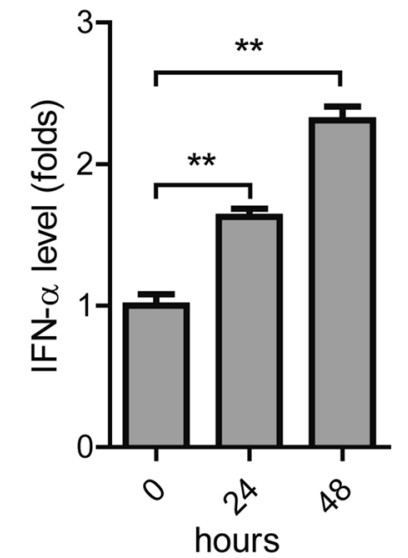

J
C BEAS-2B cell line

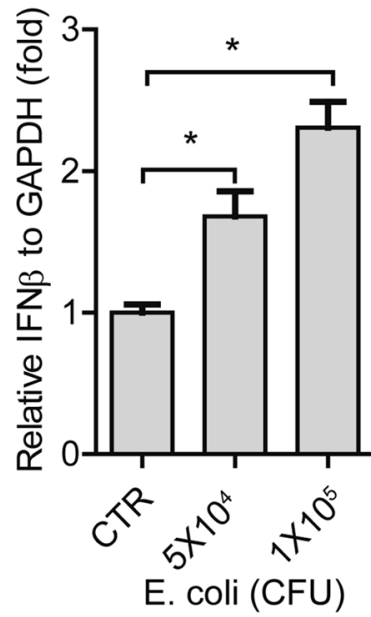

E. coli (CFU)

$\mathbf{F}$

HFL1 cell line

G

BEAS-2B cell line

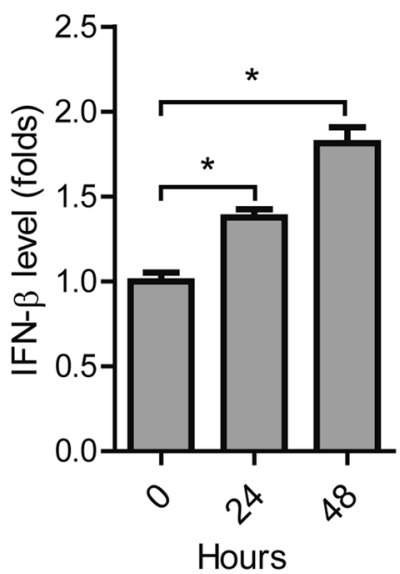

H
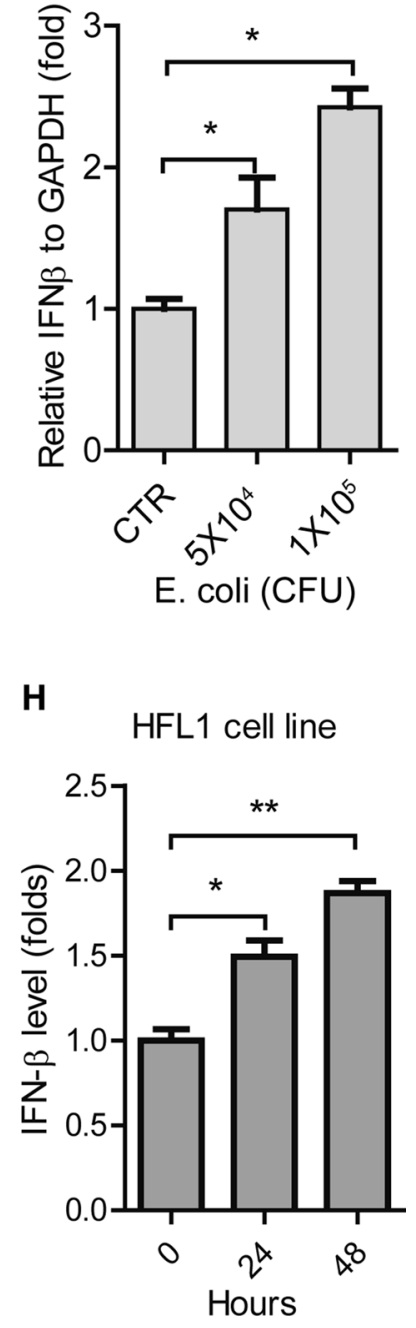
BEAS-2B cell line

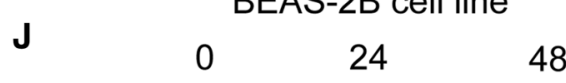

IFN- $\alpha$

IFN- $\beta$

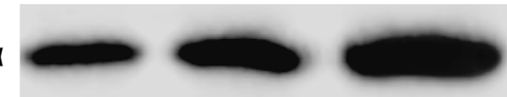

GAPDH

$n=4, * P<0.05)$ and the HFL1 cell line (Fig. 1D, $n=4$, $* P<0.05)$. ELISAs were performed to further investigate the effects of $E$. coli infections on IFN- $\alpha$ and IFN- $\beta$ secretion, which indicated that $E$. coli infections $\left(5 \times 10^{4} \mathrm{CFU}\right)$ significantly increased IFN- $\alpha$ secretion in the BEAS-2B cell 
४Fig. 1 E. coli infections increased the expression levels of IFN- $\alpha$ and IFN $-\beta$ in lung cells. A $E$. coli infections $(5 \times 104$ and $1 \times 105$ CFU, $24 \mathrm{~h})$ significantly increased mRNA expression of IFN- $\alpha$ in the BEAS-2B cell line $(n=4, * P<0.05, * * P<0.01)$; E. coli infections $(5 \times 104$ and $1 \times 105 \mathrm{CFU}, 24 \mathrm{~h})$ significantly increased mRNA expression of IFN- $\alpha$ in the HFL1 cell line $(n=4, * P<0.05) ; \mathbf{C}$ E. coli infections $(5 \times 104$ and $1 \times 105 \mathrm{CFU}, 24 \mathrm{~h})$ significantly increased mRNA expression of IFN- $\beta$ in the BEAS-2B cell line $(n=4, * P<0.05)$; D E. coli infections $(5 \times 104$ and $1 \times 105 \mathrm{CFU}$, $24 \mathrm{~h})$ significantly increased mRNA expression of IFN- $\beta$ in the HFL1 cell line $\left(n=4,{ }^{*} P<0.05\right)$. E. coli infections $\left(5 \times 10^{4} \mathrm{CFU}\right)$ significantly increased IFN- $\alpha$ secretion in the BEAS-2B cell line $(\mathbf{E}, n=4$, $* P<0.05, * * P<0.01)$ and HFL1 cell line $(\mathbf{F}, n=4, * * P<0.01)$ over time ( 24 and 48 h). E. coli infections $\left(5 \times 10^{4} \mathrm{CFU}\right)$ significantly increased IFN- $\beta$ secretion in the BEAS-2B cell line $(\mathbf{G}, n=4$, $* P<0.05)$ and HFL1 cell line $(\mathbf{H}, n=4, * P<0.05, * * P<0.01)$ over time (24 and 48 h). I E. coli infections $\left(5 \times 10^{4} \mathrm{CFU}\right)$ significantly increased IFN- $\alpha$ and IFN- $\beta$ protein levels in the BEAS-2B cell line over time (24 and $48 \mathrm{~h})$; J E. coli infections $\left(5 \times 10^{4} \mathrm{CFU}\right)$ significantly increased IFN- $\alpha$ and IFN- $\beta$ secretion in the HFL1 cell line over time (24 and $48 \mathrm{~h}$ )

line (Fig. 1E, $n=4, * P<0.05, * * P<0.01$ ) and the HFL1 cell line (Fig. 1F, $n=4, * * P<0.01$ ) over time. Similarly, we found that $E$. coli infection $\left(5 \times 10^{4} \mathrm{CFU}\right)$ significantly increased IFN- $\beta$ secretion in the BEAS-2B cell line (Fig. 1G, $n=4, * P<0.05$ ) and the HFL1 cell line (Fig. $1 \mathrm{H}, n=4$, $* P<0.05, * * P<0.01)$ over time. WB assays indicated that E. coli infection $\left(5 \times 10^{4} \mathrm{CFU}\right)$ significantly increased IFN- $\alpha$ and IFN- $\beta$ protein levels in the BEAS-2B cell line (Fig. 1I) over time, and E. coli infection $\left(5 \times 10^{4} \mathrm{CFU}\right)$ significantly increased IFN- $\alpha$ and IFN- $\beta$ protein levels in the HFL1 cell line (Fig. 1J) over time. Thus, we confirmed that E. coli infection could increase the expression levels of IFN- $\alpha$ and IFN- $\beta$ in lung cells.

\section{E. coli infections increased the expression levels of the main components of the JAK1/STAT signaling pathway in lung cells}

The JAK/STAT signaling pathway plays an important role in innate immunity (Yan et al. 2018). Thus, key genes, including JAK1, STAT1, and STAT2, in the JAK/STAT signaling pathways were studied. E. coli infections $(5 \times 104$ and $1 \times 105 \mathrm{CFU})$ significantly increased the mRNA expression of JAK1 in the BEAS-2B cell line (Fig. 2A, $n=4$, $* P<0.05)$. In parallel, $E$. coli infections $(5 \times 104$ and $1 \times 105 \mathrm{CFU}$ ) remarkably increased the mRNA levels of STAT1 (Fig. 2B, $n=4, * P<0.05$ ) and STAT2 (Fig. 2C, $n=4, * P<0.05, * * P<0.01)$ in the BEAS-2B cell line. Similarly, E. coli infections $(5 \times 104$ and $1 \times 105 \mathrm{CFU})$ significantly increased the mRNA levels of JAK1 (Fig. 2D, $n=4$, $* P<0.05, * * P<0.01$ ), STAT1 (Fig. 2E, $n=4, * P<0.05$ ) and STAT2 (Fig. 2F, $n=4,{ }^{*} P<0.05$ ) in the HFL1 cell line. Moreover, $E$. coli infection $(5 \times 104 \mathrm{CFU})$ increased phosphorylation level of JAK1, STAT1, and STAT2 in BEAS-2B cell line over time (Fig. 2G). E. coli infection $(5 \times 104$ CFU) increased phosphorylation level of JAK1, STAT1, and STAT2 in BEAS-2B cell line over time (Fig. 2H). Taken together, these results demonstrated that $E$. coli infection could increase the expression levels of key genes of the JAK1/STAT signaling pathway in lung cells.

\section{E. coli infections increased the expression levels of interferon-stimulated genes (ISGs) in lung cells}

ISGs are downstream genes of the JAK/STAT signaling pathway (Ivashkiv and Donlin 2014). Therefore, we investigated the effects of $E$. coli infections on the expression of several ISGs, including ISG20, MX1, and IFIT1. E. coli infections $\left(5 \times 10^{4}\right.$ and $\left.1 \times 10^{5} \mathrm{CFU}\right)$ significantly increased the mRNA expression of ISG20 (Fig. 3A, $n=4, * * P<0.01, * * * P<0.001$ ), MX1 (Fig. 3B, $n=4$, $* * P<0.01, * * * P<0.001$ ), and IFIT1 (Fig. 3C, $n=4$, ** $P<0.01$, *** $P<0.001)$ in the BEAS-2B cell line. In parallel, E. coli infections $\left(5 \times 10^{4}\right.$ and $\left.1 \times 10^{5} \mathrm{CFU}\right)$ significantly increased the mRNA expression of ISG20 (Fig. 3D, $n=4, * * * P<0.001$ ), MX1 (Fig. 3E, $n=4, * * P<0.01$, $* * * P<0.001$ ), and IFIT1 (Fig. $3 \mathrm{~F}, n=4, * * P<0.01$, $* * * P<0.001)$ in the HFL1 cell line. Thus, the $E$. coli infections could increase the expression level of ISGs in lung cells.

\section{JAK1 knockdown compromised the E. coli infection-mediated enhancement of the expression levels of IFN- $\alpha$ and IFN- $\beta$ in lung cells}

To further investigate the effects of JAK1/STAT signaling on IFN- $\alpha$ and IFN- $\beta$ production by $E$. coli infections in lung cells, we performed a siRNA-based JAK1 knockdown assay. The qRT-PCR assay demonstrated successful knockdown of JAK1 in the BEAS-2B (Fig. 4A, $n=4, * * P<0.01$ ) and HFL1 cell lines (Fig. 4B, $n=4, * P<0.05$ ). To further verify this hypothesis, we carried out a WB experiment, which indicated that siRNA against JAK1 could knock down the expression in the BEAS-2B cell line (Fig. 4C) and the HFL1 cell line (Fig. 4D) at the protein level. Interestingly, JAK1 knockdown abolished the $E$. coli infection $\left(1 \times 10^{5} \mathrm{CFU}\right)$ mediated enhancement of the expression levels of IFN- $\alpha$ (Fig. 4E, $n=4, * * P<0.01$ ) and IFN- $\beta$ (Fig. 4F, $n=4$, $* P<0.05, * * P<0.01)$ in the BEAS-2B cell line. Similarly, JAK1 knockdown abolished the $E$. coli infection $\left(1 \times 10^{5} \mathrm{CFU}\right)$-mediated enhancement of the expression levels of IFN- $\alpha$ (Fig. $4 \mathrm{G}, n=4, * * P<0.01$ ) and IFN- $\beta$ (Fig. $4 \mathrm{H}, n=4, * * P<0.01, * * * P<0.001$ ) in the HFL1 cell line. Therefore, JAK1 knockdown could abolish the E. coli infection-mediated enhancement of the expression levels of IFN- $\alpha$ and IFN- $\beta$ in lung cells. 


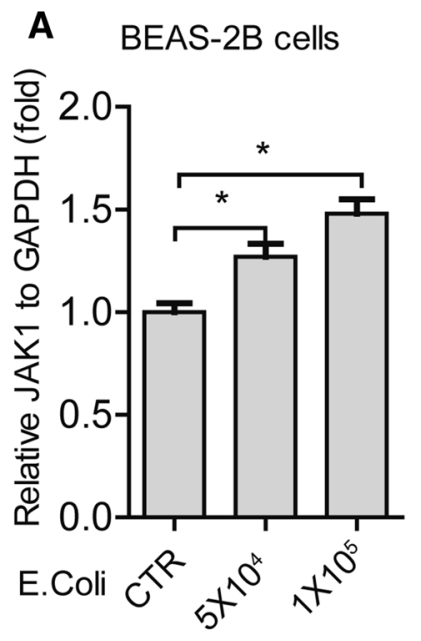

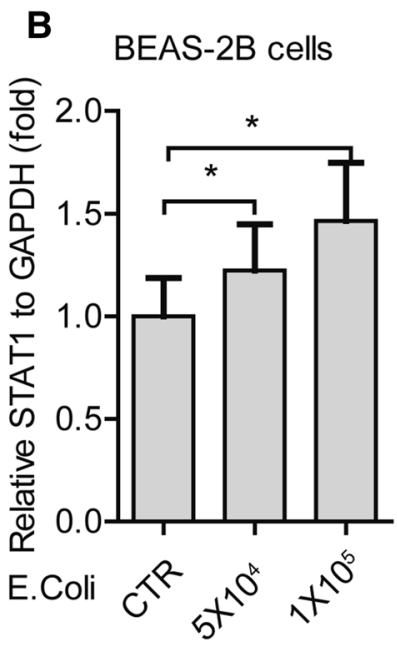

C BEAS-2B cells
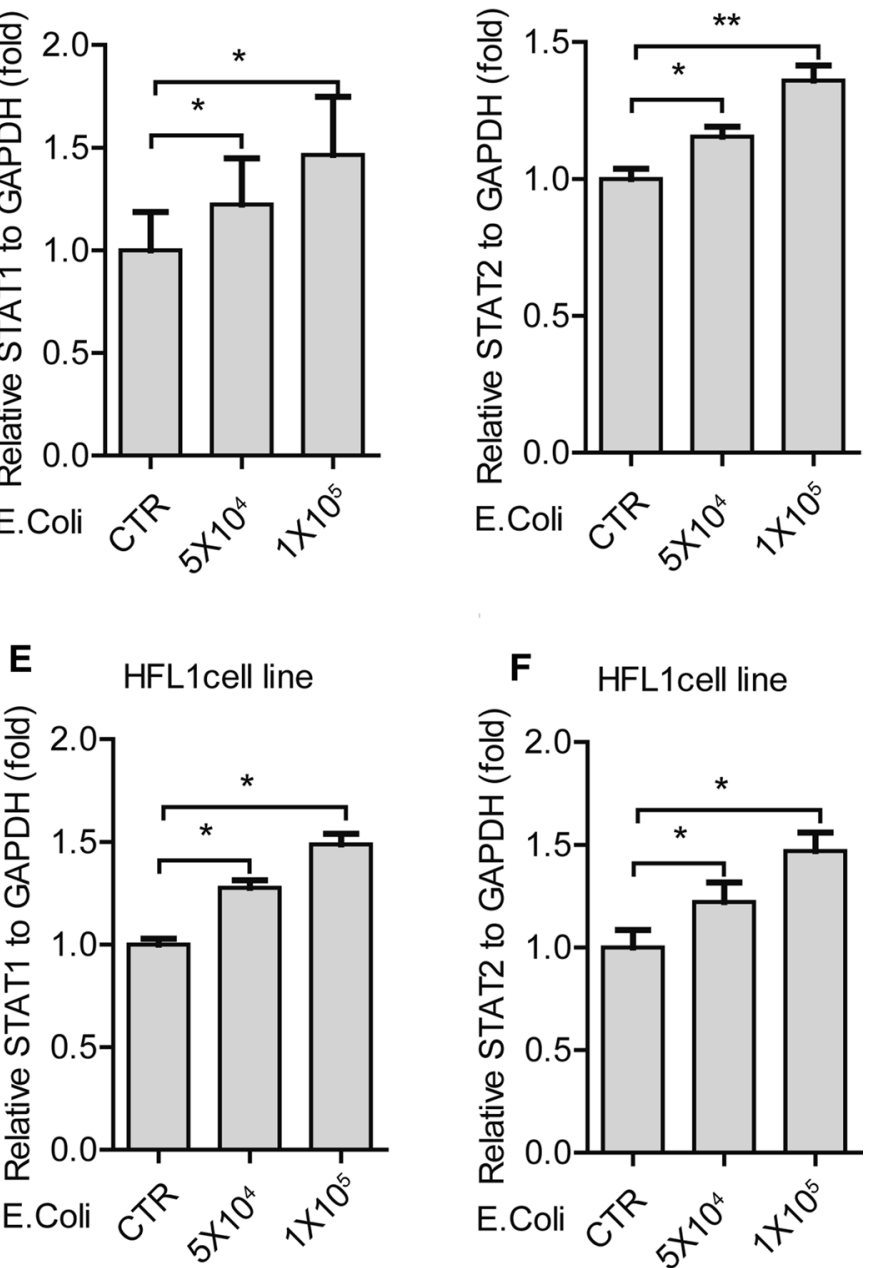

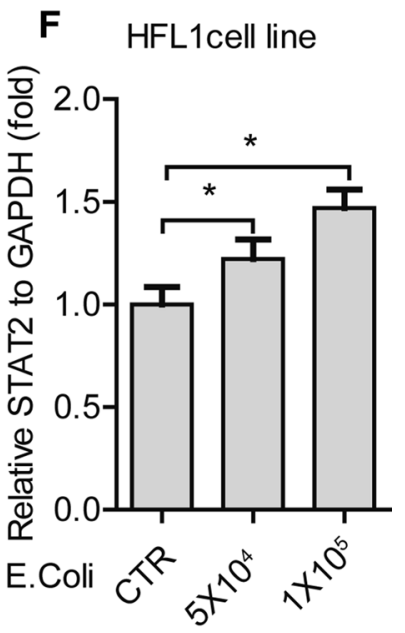

G

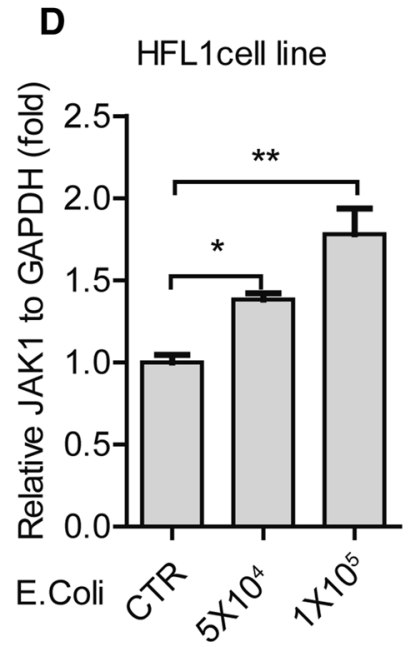

H

$$
\text { P-JAK1 }
$$

0

24

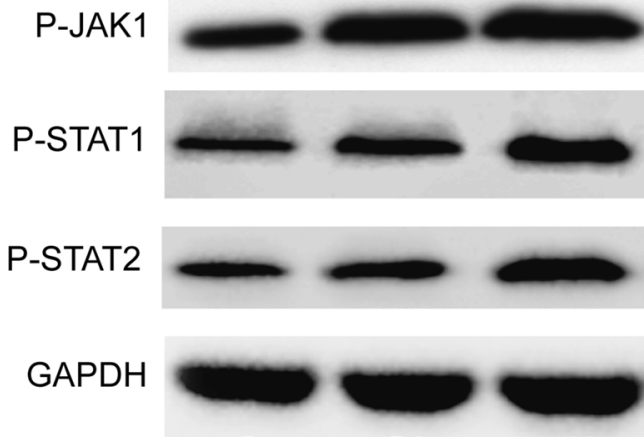

STAT1 knockdown compromised the $E$. coli infection-mediated enhancement of the expression levels of IFN- $\alpha$ and IFN- $\beta$ in lung cells

To further verify how JAK/STAT signaling influences $E$. coli-induced infections, we used siRNA against STAT1, which indicated that the siRNA significantly knocked down STAT1 in the BEAS-2B cell line (Fig. 5A, $n=4, * * P<0.01$ ) and the HFL1 cell line (Fig. 5B, $n=4, * * * P<0.001$ ). Moreover, siRNA against STAT1 could reduce the protein 
4 Fig. 2 E. coli infections increased the expression levels of the main components of the JAK1/STAT signaling pathway in lung cells. A E. coli infections $(55 \times 104$ and $1 \times 105 \mathrm{CFU}, 24 \mathrm{~h})$ significantly increased mRNA expression of JAK1 in the BEAS-2B cell line $(n=4, * P<0.05)$; B E. coli infections $(5 \times 104$ and $1 \times 105 \mathrm{CFU}$, $24 \mathrm{~h})$ remarkably increased the mRNA levels of STAT1 in the BEAS-2B cell line $(n=4, * P<0.05)$; C E. coli infections $(5 \times 104$ and $1 \times 105 \mathrm{CFU}, 24 \mathrm{~h}$ ) remarkably increased the mRNA levels of STAT2 $(n=4, * P<0.05, * * P<0.01)$; D E. coli infections $(5 \times 104$ and $1 \times 105 \mathrm{CFU}, 24 \mathrm{~h}$ ) significantly increased the mRNA levels of JAK1 in the HFL1 cell line $(n=4, * P<0.05, * * P<0.01)$; $\mathbf{E}$ E. coli infections $(5 \times 104$ and $1 \times 105 \mathrm{CFU}, 24 \mathrm{~h})$ significantly increased the mRNA levels of STAT1 in the HFL1 cell line $(n=4, * P<0.05)$; F $E$. coli infections $(5 \times 104$ and $1 \times 105 \mathrm{CFU}, 24 \mathrm{~h})$ significantly increased the mRNA levels of STAT2 in the HFL1 cell line $(n=4, * P<0.05)$. G $E$. coli infection $(5 \times 104 \mathrm{CFU})$ increased phosphorylation level of JAK1, STAT1, and STAT1 in BEAS-2B cell line over time (24 and 48 h). H E. coli infection $(5 \times 104 \mathrm{CFU})$ increased phosphorylation level of JAK1, STAT1, and STAT1 in HFL1 cell line over time (24 and $48 \mathrm{~h}$ )

levels of STAT1 in the BEAS-2B cell line (Fig. 5C) and the HFL1 cell line (Fig. 5D), as shown by WB assays. Moreover, STAT1 knockdown abolished the E. coli infection $\left(1 \times 10^{5} \mathrm{CFU}\right)$-mediated enhancement of the expression levels of IFN- $\alpha$ (Fig. 5E, $n=4, * * P<0.01$ ) and IFN- $\beta$ (Fig. 5F, $n=4, * * P<0.01)$ in the BEAS-2B cell line. STAT1 knockdown also abolished the $E$. coli infection $\left(1 \times 10^{5} \mathrm{CFU}\right)$ mediated enhancement of the expression levels of IFN- $\alpha$ (Fig. 5G, $n=4, * * P<0.01$ ) and IFN- $\beta$ (Fig. 5H, $n=4$, $* P<0.05)$ in the HFL1 cell line. Therefore, STAT1 knockdown abolished the $E$. coli infection-mediated enhancement of the expression levels of IFN- $\alpha$ and IFN $-\beta$ in lung cells.

\section{STAT2 knockdown compromised the $E$. coli infection-mediated enhancement of the expression levels of IFN- $\boldsymbol{\alpha}$ and IFN- $\beta$ in lung cells}

To further investigate how the JAK1/STAT pathway is involved in the effects of $E$. coli infections on IFN- $\alpha$ and IFN- $\beta$ production, we used siRNA against STAT2 to knock down the gene expression in both lung cell lines; we found that the expression level of STAT2 was significantly reduced in the BEAS-2B cell line (Fig. 6A, $n=4, * * P<0.01$ ) and the HFL1 cell line (Fig. 6B, $n=4,{ }^{* *} P<0.01$ ). It was also found that siRNA against STAT2 could reduce the protein level of STAT1 in the BEAS-2B cell line (Fig. 6C) and the HFL1 cell line (Fig. 6D), as shown via WB assays. STAT1 knockdown abolished the $E$. coli infection $\left(1 \times 10^{5} \mathrm{CFU}\right)$-mediated enhancement of the expression levels of IFN- $\alpha$ (Fig. 6E, $n=4, * * P<0.01$ ) and IFN- $\beta$ (Fig. $6 \mathrm{~F}, n=4, * * P<0.01$ ) in the BEAS-2B cell line. Similarly, STAT1 knockdown abolished the $E$. coli infection $\left(1 \times 10^{5} \mathrm{CFU}\right)$-mediated enhancement of the expression levels of IFN- $\alpha$ (Fig. $6 \mathrm{G}$, $n=4, * * P<0.01$ ) and IFN- $\beta$ (Fig. $6 \mathrm{H}, n=4, * P<0.05$ ) in the HFL1 cell line. Herein, it was demonstrated that STAT2 knockdown could abolish the $E$. coli infection-mediated enhancement of the expression level of IFN- $\alpha$ and IFN- $\beta$ in lung cells.

\section{Silencing JAK1, STAT1, and STAT2 abolished the $E$. coli infection-mediated promotion of the expression level of ISGs in lung cells}

To further demonstrate how the JAK1/STAT pathway is involved in IFN- $\alpha$ and IFN- $\beta$ production induced by $E$. coli infections, we investigated the effects of JAK1, STAT1, and STAT2 knockdown on the E. coli regulation of the expression level of ISGs in lung cells. JAK1 knockdown abolished the $E$. coli infection $\left(1 \times 10^{5} \mathrm{CFU}\right)$-mediated enhancement of the expression of ISGs, including ISG20, MX1, and IFIT1, in the BEAS-2B cell line (Fig. 7A, $n=4, * * P<0.01$ ). Similarly, STAT1 (Fig. 7B, $n=4, * P<0.05$, $* * P<0.01$ ) and STAT2 (Fig. 7C, $n=4, * * P<0.01$ ) knockdown abolished the $E$. coli infection $\left(1 \times 10^{5} \mathrm{CFU}\right)$-mediated enhancement of the expression of ISGs, including ISG20, MX1, and IFIT1, in the BEAS-2B cell line. Similarly, knockdown of JAK1 (Fig. 7D, $n=4, * P<0.05, * * P<0.01$ ), STAT1 (Fig. 7E, $n=4, * P<0.05, * * P<0.01$ ), and STAT2 (Fig. 7F, $n=4, * P<0.05, * * P<0.01)$ abolished the $E$. coli infection $\left(1 \times 10^{5} \mathrm{CFU}\right)$-mediated enhancement of the expression of ISGs, including ISG20, MX1, and IFIT1, in the HFL1 cell line. Thus, we confirmed that knockdown of JAK1, STAT1, and STAT2 could abolish the E. coli infection-mediated enhancement of the expression level of ISGs in lung cells.

\section{Discussion}

The lung is an organ that accesses air and contains many microorganisms (Lee et al. 2009). Among them, E. coli is one of the most common pathogens infecting lung tissues to cause lung injury (Masterson et al. 2018). It was reported that $E$. coli infections could induce innate immune responses in the lung tissue (Martin and Frevert 2005). However, it remains unclear how $E$. coli infections induce IFN- $\alpha$ and IFN- $\beta$ production in lung cells. Thus, in this study, it was found that $E$. coli infection significantly increased the expression of IFN- $\alpha$ and IFN- $\beta$, ISGs, and key genes of JAK1/STAT signaling. Importantly, we found that knockdown of JAK1, STAT1, and STAT2 could abolish the $E$. coli infection-mediated promotion of the expression levels of IFN- $\alpha$ and IFN- $\beta$ and ISGs. Taken together, these results demonstrated that $E$. coli infections induced interferon production in lung cells, which was regulated by the JAK1/ STAT signaling pathway.

Lung cells are a critical source of innate immune molecules (Sturrock et al. 2018). It was found that the innate immune response is closely related to acute lung injury 

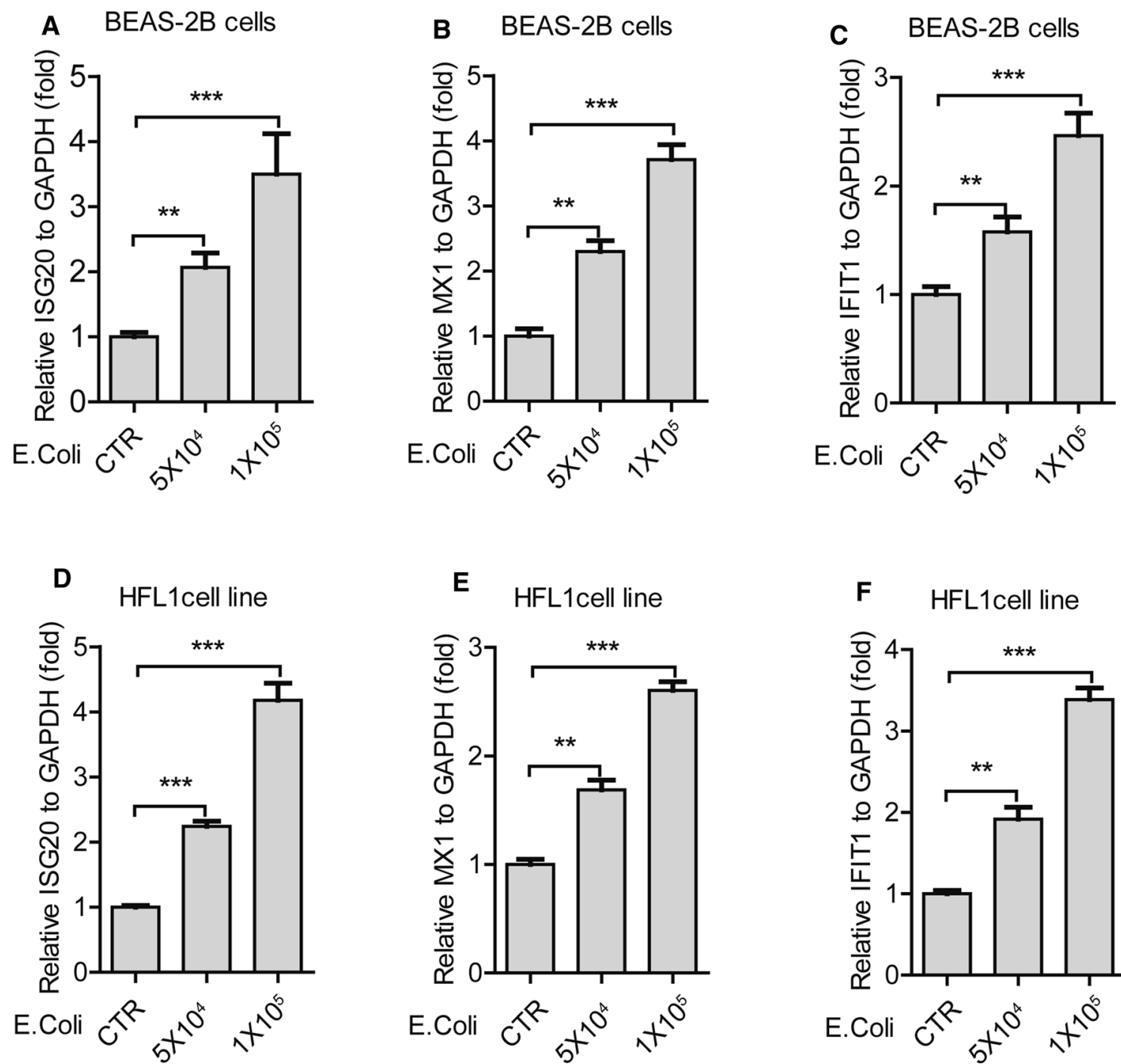

E HFL1cell line

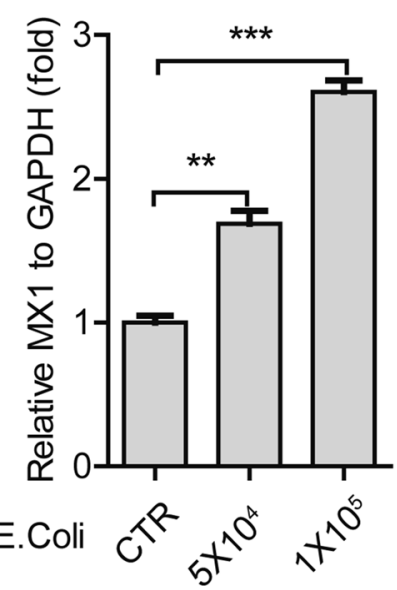

F HFL1cell line

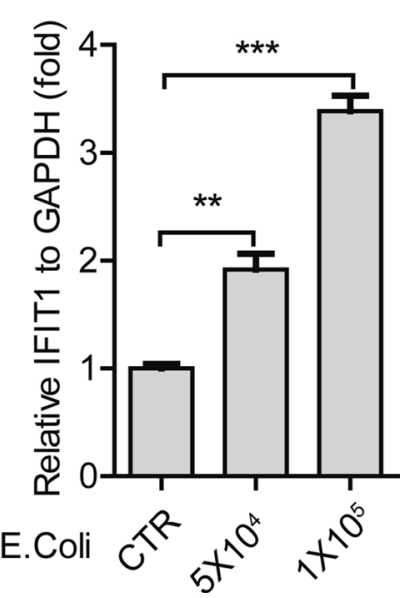

Fig. 3 E. coli infections increased the expression level of interferonstimulated genes (ISGs) in lung cells. A E. coli infections $(5 \times 104$ and $1 \times 105 \mathrm{CFU}, 24 \mathrm{~h}$ ) significantly increased the mRNA expression of ISG20 in the BEAS-2B cell line $(n=4, * * P<0.01, * * * P<0.001)$; B E. coli infections $(5 \times 104$ and $1 \times 105 \mathrm{CFU}, 24 \mathrm{~h})$ significantly increased the mRNA expression of MX1 in the BEAS-2B cell line $(n=4, * * P<0.01, * * * P<0.001)$; C E. coli infections $(5 \times 104$ and $1 \times 105 \mathrm{CFU}, 24 \mathrm{~h})$ significantly increased the mRNA expression of IFIT1 in the BEAS-2B cell line $(n=4, * * P<0.01, * * * P<0.001)$;

(Maijo et al. 2012; Wang et al. 2013). Thus, understanding innate immunity in the lung will help identify an effective approach to treating lung injury. Many bacteria have been confirmed to induce innate immunity, including IFN- $\alpha$ and IFN- $\beta$ production; for example, it was reported that Streptococcus pneumoniae and Staphylococcus aureus induced the expression of IFN- $\gamma$ mRNA and protein in the lungs of mice (Yamada et al. 2011). Pseudomonas aeruginosa was found to induce the type I interferon signaling pathway in the lung (Parker and Prince 2011). The levels of innate
D E. coli infections $(5 \times 104$ and $1 \times 105 \mathrm{CFU}, 24 \mathrm{~h})$ significantly increased the mRNA expression of ISG20 in the HFL1 cell line $(n=4, * * * P<0.001) ; \mathbf{E}$ E. coli infections $(5 \times 104$ and $1 \times 105 \mathrm{CFU}$, $24 \mathrm{~h})$ significantly increased the mRNA expression of MX1 in the HFL1 cell line $(n=4, * * P<0.01, * * * P<0.001)$; F E. coli infections $(5 \times 104$ and $1 \times 105 \mathrm{CFU}, 24 \mathrm{~h})$ significantly increased the mRNA expression of IFIT1 in the HFL1 cell line $(n=4, * * P<0.01$, $* * * P<0.001)$

immunity-related genes, including TNF- $\alpha$ and IL-6, were increased by $E$. coli LPS treatment in the lungs of mice (Jeyaseelan et al. 2007). An avian E. coli strain named avian pathogenic E. coli (APEc) was reported to significantly increase the expression levels of the inflammatory cytokines IL-1 $\beta$, IL-18, and TNF- $\alpha$ in the lung (Li et al. 2018). Similarly, in the present study, we found that $E$. coli infection induced type I innate immunity, including an increase in the expression levels of IFN- $\alpha$ and IFN- $\beta$ and ISGs (Figs. 1 and 2). 

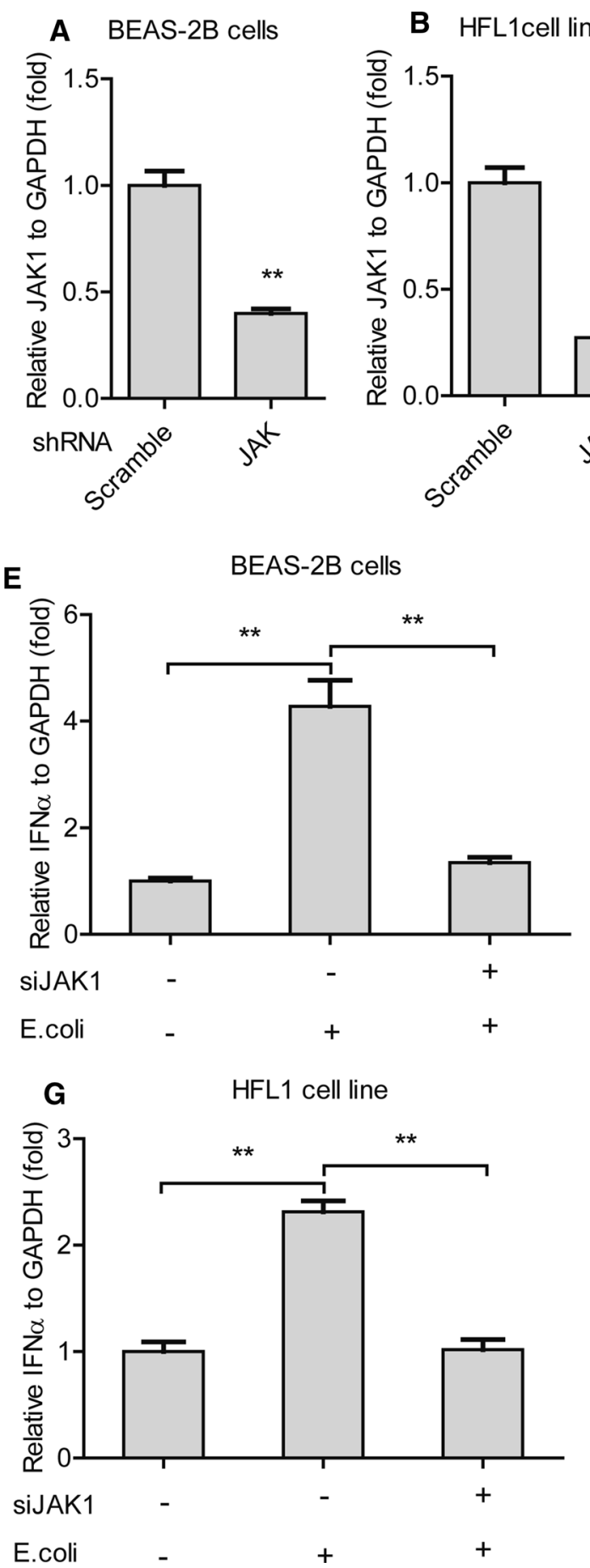

Fig. 4 JAK1 knockdown compromised the E. coli infection-mediated enhancement of on the expression levels of IFN- $\alpha$ and IFN- $\beta$ in lung cells. A JAK1 was successfully knocked down in the BEAS-2B cell line, as shown using qPCR assays $(n=4, * * P<0.01)$; B JAK1 was successfully knocked down in the HFL1 cell line, as shown using qPCR assays $(n=4, * P<0.05)$; C JAK1 was successfully knocked down in the BEAS-2B cell line, as shown using WB assays; D JAK1 was successfully knocked down in the HFL1 cell line, as shown using WB assays; E JAK1 knockdown abolished the $E$. coli infection $(1 \times 105 \mathrm{CFU}, 24 \mathrm{~h})$-mediated enhancement of the expression level of

\section{C \\ BEAS-2B cells D HFL1cell line}

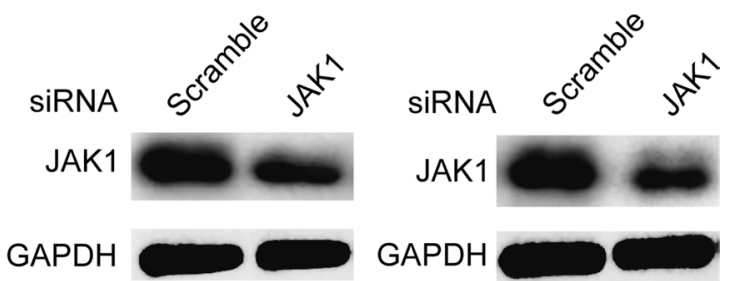

* GAPDH GAPDH
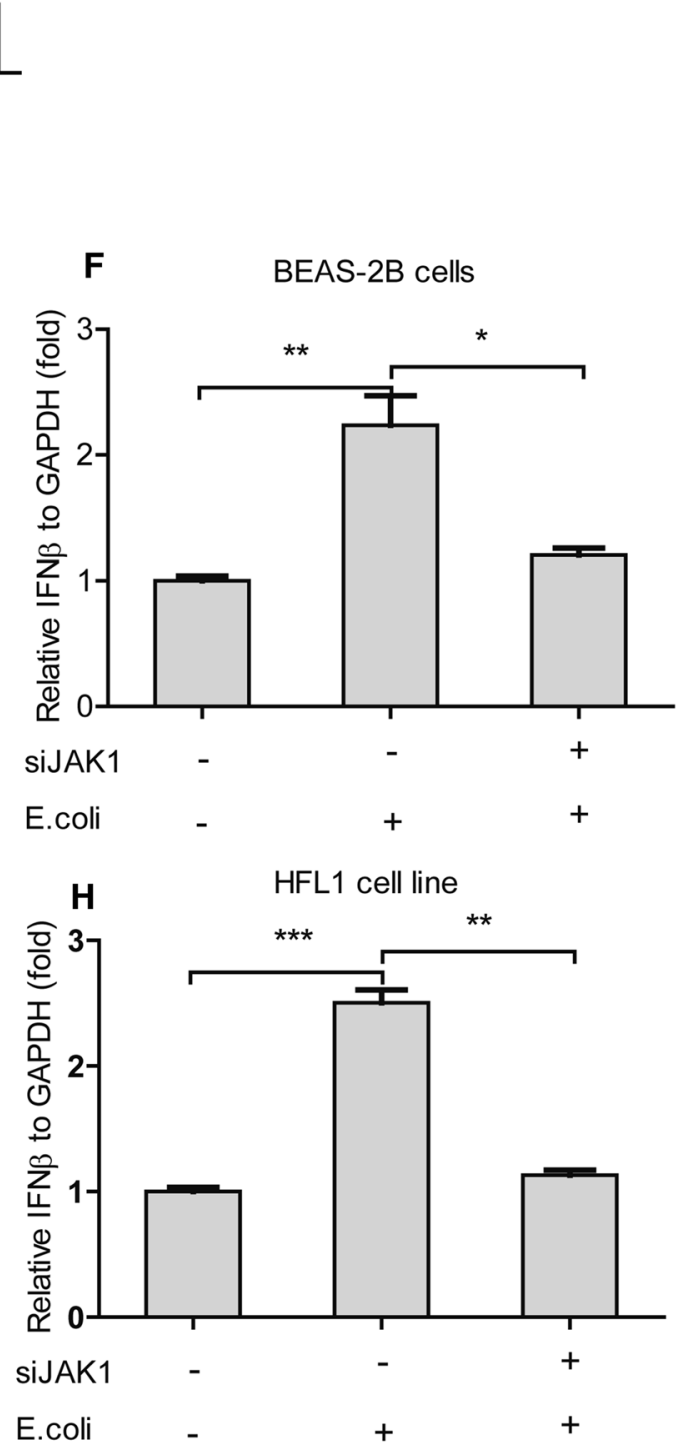

IFN- $\alpha$ in the BEAS-2B cell line $(n=4, * * P<0.01)$; F JAK1 knockdown abolished the $E$. coli infection $(1 \times 105 \mathrm{CFU}, 24 \mathrm{~h})$-mediated enhancement of the expression level of IFN- $\beta$ in the BEAS-2B cell line $(n=4, * P<0.05, * * P<0.01)$; G JAK1 knockdown abolished the $E$. coli infection $(1 \times 105 \mathrm{CFU}, 24 \mathrm{~h})$-mediated enhancement of the expression level of IFN- $\alpha$ in the HFL1 cell line $(n=4, * * P<0.01) ; \mathbf{H}$ JAK1 knockdown abolished the $E$. coli infection $(1 \times 105$ CFU, 24 h)mediated enhancement of the expression level of IFN- $\beta$ in the HFL1 cell line $(n=4, * * P<0.01, * * * P<0.001)$ 
A BEAS-2B cells
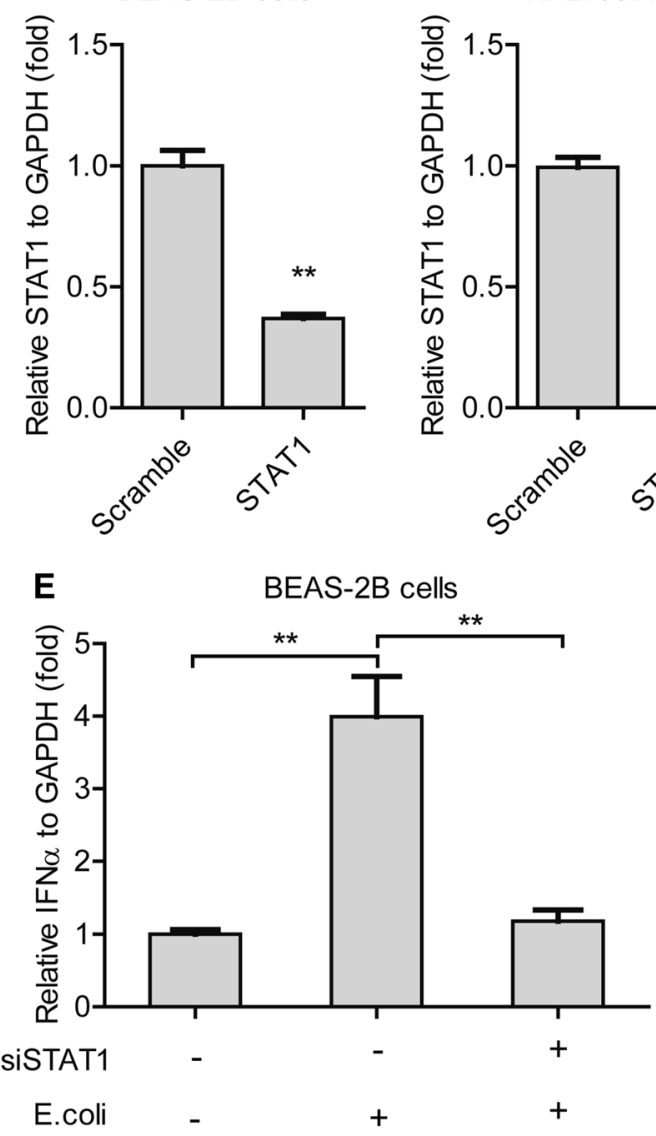

G

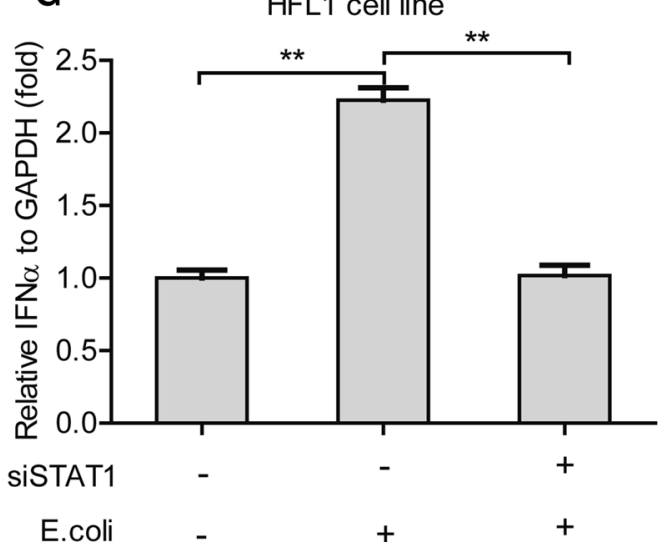

Fig. 5 STAT1 knockdown compromised the E. coli infection-mediated enhancement of the expression levels of IFN- $\alpha$ and IFN- $\beta$ in lung cells. A STAT1 was successfully knocked down in the BEAS2B cell line, as shown using qPCR assays $(n=4, * * P<0.01)$; B STAT1 was successfully knocked down in the HFL1 cell line, as shown using qPCR assays $(n=4, * * P<0.01)$; C STAT1 was successfully knocked down in the BEAS-2B cell line, as shown using WB assays; D STAT1 was successfully knocked down in the HFL1 cell line, as shown using WB assays; E STAT1 knockdown could abolish the $E$. coli infection $(1 \times 105 \mathrm{CFU}, 24 \mathrm{~h})$-mediated enhancement
C BEAS-2B cells

D HFL1cell line

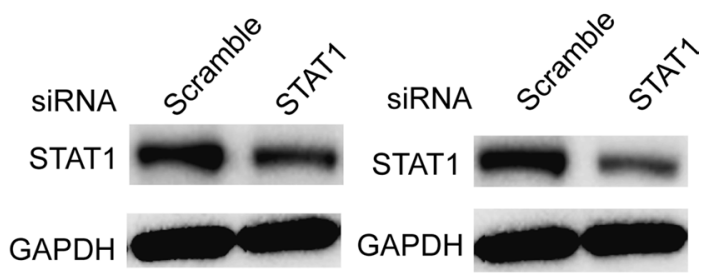

$\mathbf{F}$

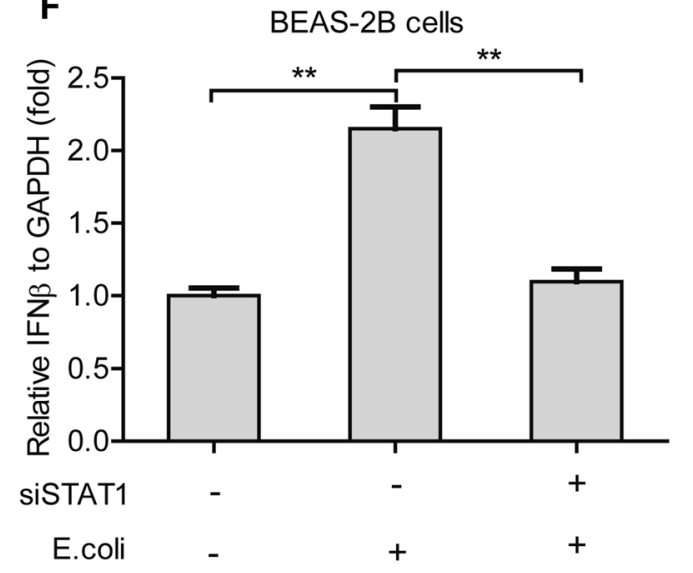

H

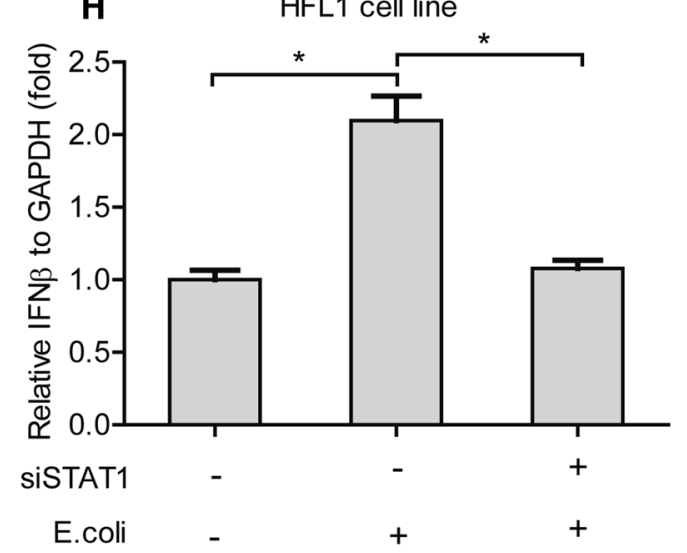

of the expression level of IFN- $\alpha$ in the BEAS-2B cell line $(n=4$, $* * P<0.01)$; F STAT1 knockdown could abolish the $E$. coli infection $(1 \times 105 \mathrm{CFU}, 24 \mathrm{~h})$-mediated enhancement of the expression level of IFN- $\beta$ in the BEAS-2B cell line $(n=4, * P<0.05, * * P<0.01)$; $\mathbf{G}$ STAT1 knockdown could abolish the $E$. coli infection $(1 \times 105 \mathrm{CFU}$, $24 \mathrm{~h}$ )-mediated enhancement of the expression level of IFN- $\alpha$ in the HFL1 cell line $(n=4, * * P<0.01)$; H STAT1 knockdown could abolish the $E$. coli infection $(1 \times 105 \mathrm{CFU}, 24 \mathrm{~h})$-mediated enhancement of the expression level of IFN $-\beta$ in the HFL1 cell line $(n=4$, $* * P<0.01, * * * P<0.001)$ 
A BEAS-2B cells

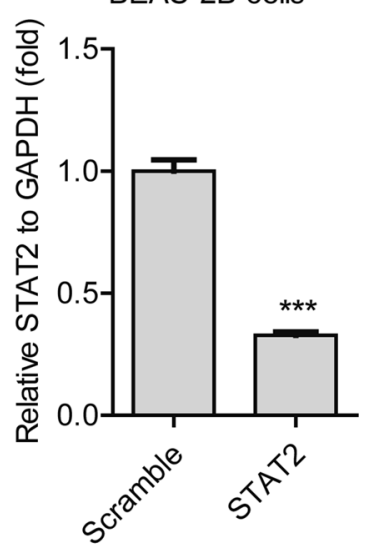

E

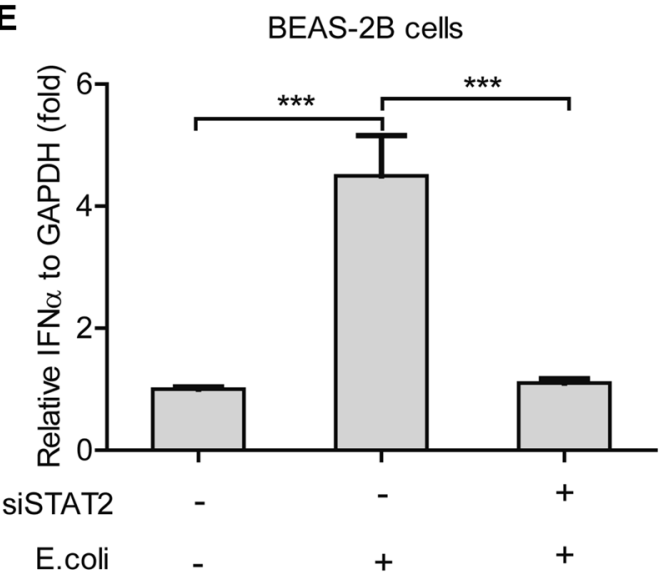

G

HFL1 cell line

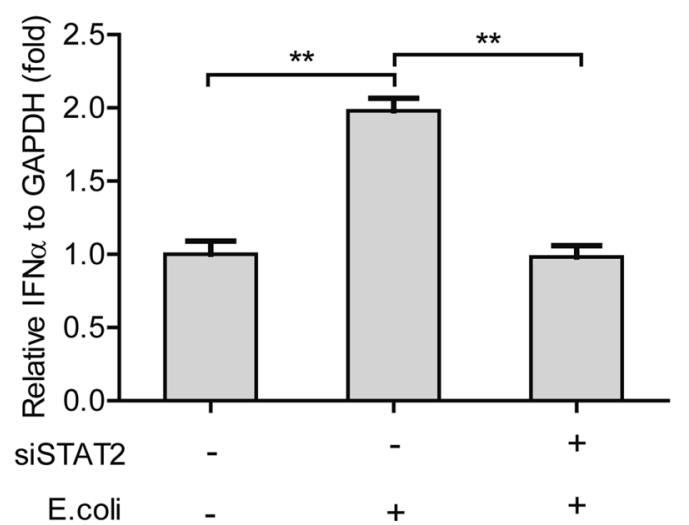

Fig. 6 STAT2 knockdown compromised the E. coli infection-mediated enhancement of the expression levels of IFN- $\alpha$ and IFN- $\beta$ in lung cells. A STAT2 was successfully knocked down in the BEAS$2 \mathrm{~B}$ cell line, as shown using $\mathrm{qPCR}$ assays $(n=4, * * P<0.01)$; $\mathbf{B}$ STAT2 was successfully knocked down in the HFL1 cell line, as shown using qPCR assays $(n=4, * * P<0.01)$; C STAT2 was successfully knocked down in the BEAS-2B cell line, as shown using WB assays; D STAT2 was successfully knocked down in the HFL1 cell line, as shown using WB assays; E STAT2 knockdown could abolish the $E$. coli infection $(1 \times 105 \mathrm{CFU}, 24 \mathrm{~h})$-mediated enhancement
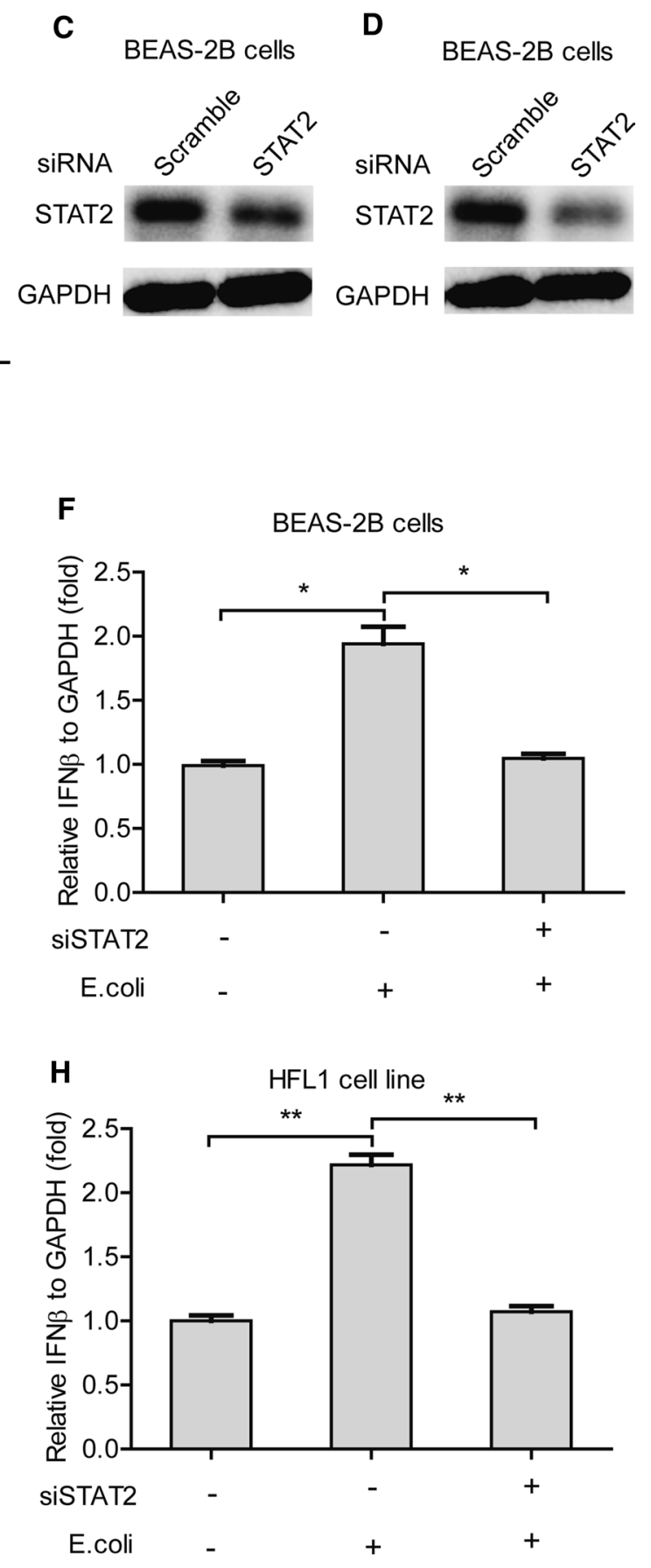

of the expression level of IFN- $\alpha$ in the BEAS-2B cell line $(n=4$, $* * P<0.01)$; F STAT2 knockdown could abolish the $E$. coli infection $(1 \times 105 \mathrm{CFU}, 24 \mathrm{~h})$-mediated enhancement of the expression level of IFN- $\beta$ in the BEAS-2B cell line $(n=4, * P<0.05$, $* * P<0.01)$; G STAT2 knockdown could abolish the $E$. coli infection $(1 \times 105$ CFU, $24 \mathrm{~h}$ )-mediated enhancement of the expression level of IFN- $\alpha$ in the HFL1 cell line $(n=4, * * P<0.01)$; (H) STAT2 knockdown could abolish the $E$. coli infection $(1 \times 105 \mathrm{CFU}, 24 \mathrm{~h})$-mediated enhancement of the expression level of IFN- $\beta$ in the HFL1 cell line $(n=4$, $* P<0.05)$ 

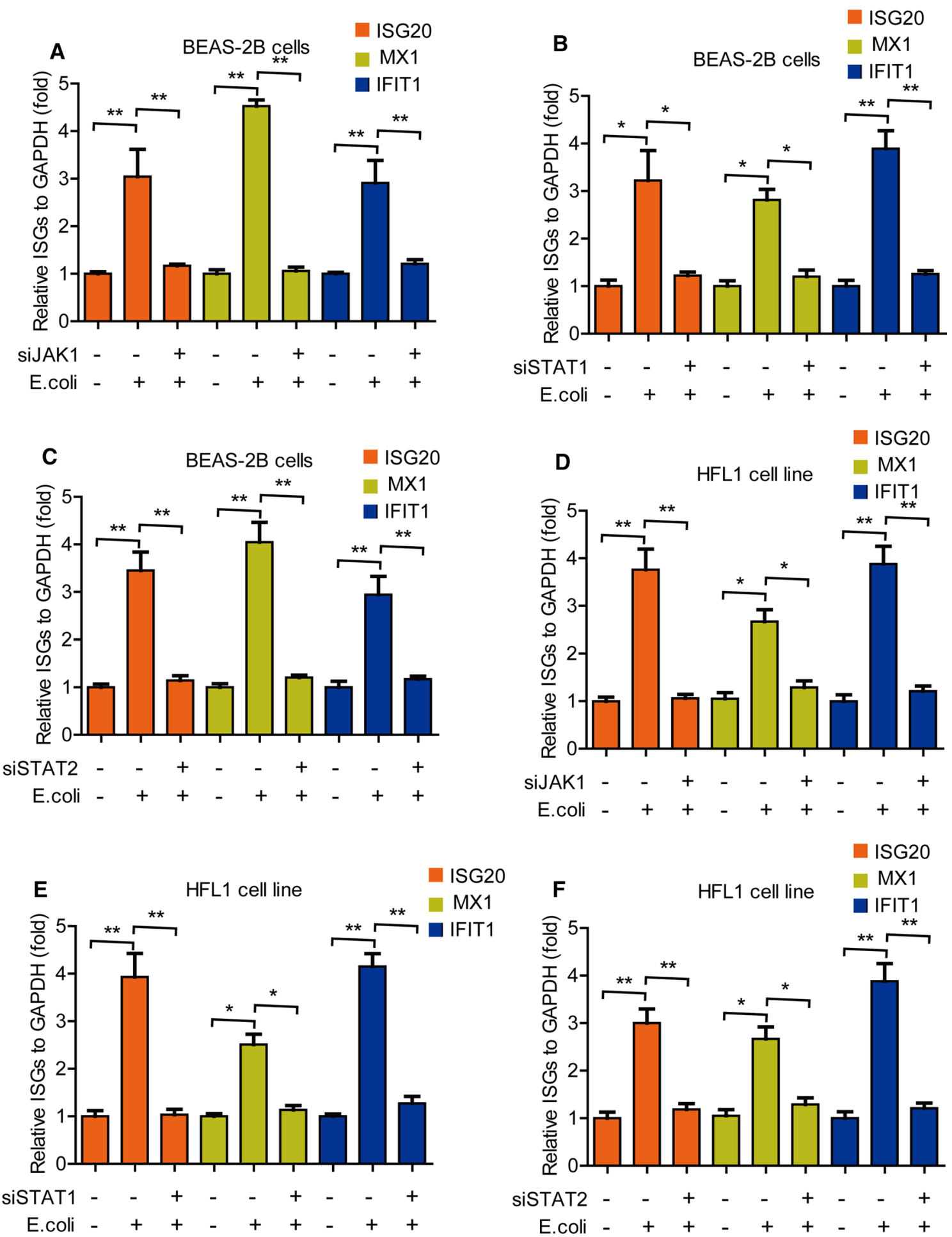

Fig. 7 Silencing JAK1, STAT1, and STAT2 abolished the E. coli infection-mediated promotion of the expression level of ISGs in lung cells. A JAK1 knockdown abolished the E. coli-mediated promotion of ISGs including ISG20, MX1, and IFIT1 in the BEAS-2B cell line $(n=4, * * P<0.01)$ B STAT1 knockdown abolished the E. colimediated promotion of ISGs including ISG20, MX1, and IFIT1 in the BEAS-2B cell line $(n=4, * P<0.05, * * P<0.01)$; C STAT2 knockdown abolished the $E$. coli-mediated promotion of ISGs including ISG20, MX1, and IFIT1 in the BEAS-2B cell line $(n=4, * * P<0.01)$;

D the knockdown of JAK1 abolished the E. coli-mediated promotion $(1 \times 105 \mathrm{CFU}, 24 \mathrm{~h})$ of ISGs including ISG20, MX1, and IFIT1 in the HFL1 cell line $(n=4, * P<0.05, * * P<0.01) ; \mathbf{E}$ the knockdown of STAT1 abolished the $E$. coli-mediated promotion $(1 \times 105 \mathrm{CFU}, 24 \mathrm{~h})$ of ISGs including ISG20, MX1, and IFIT1 in the HFL1 cell line $(n=4, * P<0.05, * * P<0.01) ; \mathbf{F}$ the knockdown of STAT2 abolished the $E$. coli-mediated promotion $(1 \times 105 \mathrm{CFU}, 24 \mathrm{~h})$ of ISGs including ISG20, MX1, and IFIT1 in the HFL1 cell line $(n=4, * P<0.05$, $* * P<0.01)$ 
The JAK/STAT pathway is one of the best understood signal transduction cascades to regulate innate immunity (Rawlings et al. 2004). JAK1 is a member of the JAK family, and its activation can phosphorylate the downstream major substrates STATs (Rawlings et al. 2004). JAK/STAT signaling directly translates an extracellular signal into a transcriptional response (Yan et al. 2018). The JAK/STAT pathway was reported to play an important role in inducing IFN-a and IFN $\gamma$ (Kohlhuber et al. 1997). Interestingly, porcine reproductive and respiratory syndrome virus (PRRSV) infection facilitated type I IFN responses by targeting JAK1 (Zhang et al. 2016). Measles virus $\mathrm{V}$ protein was reported to inhibit JAK1-mediated phosphorylation of STAT 1 to escape IFN- $\alpha / \beta$ signaling (Caignard et al. 2007). In the present study, we confirmed that $E$. coli infections significantly increased the expression of JAK1, STAT1, and STAT2 (Fig. 4), which led us to further investigate the role of JAK/STAT signaling in $E$. coli-induced IFN- $\alpha$ and IFN- $\beta$ production. By silencing major JAK1, STAT1, and STAT2 genes involved in JAK/STAT signaling, we found that JAK/STAT signaling closely regulated $E$. coli-induced IFN- $\alpha$ and IFN- $\beta$ production (Figs. 4,5 , and 6 ). Notably, knockdown of JAK1, STAT1, and STAT2 compromised the E. coli infection-mediated promotion of the expression of ISGs (Fig. 7). The aforementioned experiments strongly demonstrated the importance of JAK/STAT signaling in $E$. coli-induced IFN- $\alpha$ and IFN- $\beta$ production. Similarly, previous studies have confirmed that mimicking $E$. coli infection using lipopolysaccharide (LPS) and poly I:C stimulation could remarkably promote the expression of STAT1 and STAT2 (Wu et al. 2017). Frendéus et al. found that $E$. coli infections potently induce the IFN- $\beta$ response (Frendéus et al. 2001). Mancuso et al. also confirmed that several bacteria, including Group B Streptococ$c u s$, pneumococcus and $E$. coli, induced IFN- $\alpha$ and IFN- $\beta$, and type I IFN played an important role in protection from bacterial infection, since IFNAR ${ }^{-/-}$mice showed decreased survival and increased bacterial load (Mancuso et al. 2007). Thus, our study and others have confirmed that the IFN signaling pathway plays an essential role in $E$. coli infections.

In conclusion, we demonstrated that $E$. coli infections remarkably promoted IFN- $\alpha$ and IFN- $\beta$ production in lung cells, which was closely regulated by the JAK/STAT signaling pathway. The findings in the present study are useful for further understanding the pathogenesis of $E$. coli infections in the lung and finding novel therapies to treat E. coliinduced lung injury.

\section{Data availability statement}

Raw data were generated at The First Affiliated Hospital of China Medical University. Derived data supporting the findings of this study are available from the corresponding author [Z.L.] on request.
Acknowledgements The study was supported by the National Basic Research Program of China (Grants nos. 81772053 and 81571882).

Author contributions YJ, JJ, ZJ, QC, and LG performed experiments; $\mathrm{ZL}$ designed the research; YJ and ZL wrote the manuscript; and ZL supervised the project.

\section{Declarations}

Conflict of interest The authors declare no competing financial interests.

Informed consent Not applicable.

\section{References}

Aulakh GK, Suri SS, Singh B (2014) Angiostatin inhibits acute lung injury in a mouse model. Am J Physiol Lung Cell Mol Physiol 306:L58-68

Caignard G et al (2007) Measles virus V protein blocks Jak1-mediated phosphorylation of STAT1 to escape IFN-alpha/beta signaling. Virology 368:351-362

Coskun M, Salem M, Pedersen J, Nielsen OH (2013) Involvement of JAK/STAT signaling in the pathogenesis of inflammatory bowel disease. Pharmacol Res 76:1-8

Feng F, Wu Y, Zhang S, Liu Y, Qin L, Wu Y, Yan Z, Wu W (2012) Macrophages facilitate coal tar pitch extract-induced tumorigenic transformation of human bronchial epithelial cells mediated by NF-кB. PLoS ONE 7(12):e51690

Frendéus B, Wachtler C, Hedlund M, Fischer H, Samuelsson P, Svensson M, Svanborg C (2001) Escherichia coli $\mathrm{P}$ fimbriae utilize the Toll-like receptor 4 pathway for cell activation. Mol Microbiol 40:37-51

Gotts JE et al (2018) Cigarette smoke exposure worsens acute lung injury in antibiotic-treated bacterial pneumonia in mice. Am J Physiol Lung Cell Mol Physiol 315:L25-L40

Gregory DJ, Kobzik L (2015) Influenza lung injury: mechanisms and therapeutic opportunities. Am J Physiol Lung Cell Mol Physiol 309:L1041-1046

Grommes J, Soehnlein O (2011) Contribution of neutrophils to acute lung injury. Mol Med 17:293-307

Gurzov EN, Stanley WJ, Pappas EG, Thomas HE, Gough DJ (2016) The JAK/STAT pathway in obesity and diabetes. FEBS J 283:3002-3015

Hamacher J et al (2017) Cytokine-ion channel interactions in pulmonary inflammation. Front Immunol 8:1644

$\mathrm{Ho} \mathrm{CH}$ et al (2017) Testosterone suppresses uropathogenic Escherichia coli invasion and colonization within prostate cells and inhibits inflammatory responses through JAK/STAT-1 signaling pathway. PLoS ONE 12:e0180244

Ivashkiv LB, Donlin LT (2014) Regulation of type I interferon responses. Nat Rev Immunol 14:36-49

Jeyaseelan S et al (2007) Toll/IL-1 receptor domain-containing adaptor inducing IFN-beta (TRIF)-mediated signaling contributes to innate immune responses in the lung during Escherichia coli pneumonia. J Immunol 178:3153-3160

Kikuchi K, Kohyama T, Yamauchi Y, Kato J, Takami K, Okazaki H, Desaki M, Nagase T, Rennard SI, Takizawa H (2009) C-reactive protein modulates human lung fibroblast migration. Exp Lung Res 35:48-58

Kohlhuber F et al (1997) A JAK1/JAK2 chimera can sustain alpha and gamma interferon responses. Mol Cell Biol 17:695-706 
Lee JW, Fang X, Gupta N, Serikov V, Matthay MA (2009) Allogeneic human mesenchymal stem cells for treatment of E. coli endotoxininduced acute lung injury in the ex vivo perfused human lung. Proc Natl Acad Sci USA 106:16357-16362

Li R et al (2018) Characterization and roles of cherry valley duck NLRP3 in innate immunity during avian pathogenic Escherichia coli infection. Front Immunol 9:2300

Liu S et al (2018a) Sinomenine protects against E.coli-induced acute lung injury in mice through Nrf2-NF-kappaB pathway. Biomed Pharmacother 107:696-702

Liu J et al (2018b) Sini decoction alleviates E. coli induced acute lung injury in mice via equilibrating ACE-AngII-AT1R and ACE2Ang-(1-7)-Mas axis. Life Sci 208:139-148

Maijo M et al (2012) Dietary plasma proteins attenuate the innate immunity response in a mouse model of acute lung injury. Br J Nutr 107:867-875

Malemud CJ (2018) The role of the JAK/STAT signal pathway in rheumatoid arthritis. Ther Adv Musculoskelet Dis 10:117-127

Mancuso G, Midiri A, Biondo C, Beninati C, Zummo S, Galbo R, Tomasello F, Gambuzza M, Macrì G, Ruggeri A, Leanderson T, Teti G (2007) Type I IFN signaling is crucial for host resistance against different species of pathogenic bacteria. J Immunol 178:3126-3133

Martin TR, Frevert CW (2005) Innate immunity in the lungs. Proc Am Thorac Soc 2:403-411

Masterson C et al (2018) Syndecan-2-positive, bone marrow-derived human mesenchymal stromal cells attenuate bacterial-induced acute lung injury and enhance resolution of ventilator-induced lung injury in rats. Anesthesiology 129:502-516

Moresi V, Adamo S, Berghella L (2019) The JAK/STAT pathway in skeletal muscle pathophysiology. Front Physiol 10:500

Mullassery D, Smith NP (2015) Lung development. Semin Pediatr Surg 24:152-155

Parker D, Prince A (2011) Type I interferon response to extracellular bacteria in the airway epithelium. Trends Immunol 32:582-588

Rawlings JS, Rosler KM, Harrison DA (2004) The JAK/STAT signaling pathway. J Cell Sci 117:1281-1283

Rubenfeld GD et al (2005) Incidence and outcomes of acute lung injury. N Engl J Med 353:1685-1693
Sturrock A, Woller D, Freeman A, Sanders K, Paine R 3rd (2018) Consequences of hypoxia for the pulmonary alveolar epithelial cell innate immune response. J Immunol 201:3411-3420

Suresh R, Kupfer Y, Tessler S (2000) Acute respiratory distress syndrome. N Engl J Med 343:660-661

Wan $\mathrm{T}$ et al (2016) Diet-induced obese mice exhibit altered immune responses to acute lung injury induced by Escherichia coli. Obesity (silver Spring) 24:2101-2110

Wang X, Nelson A, Weiler ZM, Patil A, Sato T, Kanaji N, Nakanishi M, Michalski J, Farid M, Basma H, Levan TD, Miller-Larsson A, Wieslander E, Muller KC, Holz O, Magnussen H, Rabe KF, Liu X, Rennard SI (2013) Anti-inflammatory effects of budesonide in human lung fibroblast are independent of histone deacetylase 2. J Inflamm Res 6:109-119

Wu Z, Wang L, Xu X, Lin G, Mao H, Ran X, Zhang T, Huang K, Wang H, Huang Q, Xu Q, Hu C (2017) Interaction of IRF9 and STAT2 synergistically up-regulates IFN and PKR transcription in Ctenopharyngodon idella. Mol Immunol 85:273-282

Yamada M et al (2011) Interferon-gamma production by neutrophils during bacterial pneumonia in mice. Am J Respir Crit Care Med 183:1391-1401

Yan Z, Gibson SA, Buckley JA, Qin H, Benveniste EN (2018) Role of the JAK/STAT signaling pathway in regulation of innate immunity in neuroinflammatory diseases. Clin Immunol 189:4-13

Ye R, Liu Z (2020) ACE2 exhibits protective effects against LPSinduced acute lung injury in mice by inhibiting the LPS-TLR4 pathway. Exp Mol Pathol 113:104350

Zhang Q et al (2016) MicroRNA-30c modulates type I IFN responses to facilitate porcine reproductive and respiratory syndrome virus infection by targeting JAK1. J Immunol 196:2272-2282

Zhu YG et al (2014) Human mesenchymal stem cell microvesicles for treatment of Escherichia coli endotoxin-induced acute lung injury in mice. Stem Cells 32:116-125

Publisher's Note Springer Nature remains neutral with regard to jurisdictional claims in published maps and institutional affiliations. 